\title{
Optimising monthly tilt angles of solar panels using particle swarm optimisation algorithm
}

Namruta S. Kanianthara, Swee Peng Ang, Ashraf Fathi Khalil Sulayman, Zainidi bin Hj. Abd. Hamid Electrical and Electronic Engineering Programme Area, Universiti Teknologi Brunei, Brunei Darussalam

\begin{tabular}{l}
\hline \hline Article Info \\
\hline Article history: \\
Received Oct 28, 2020 \\
Revised Jun 11, 2021 \\
Accepted Jun 17, 2021 \\
\hline
\end{tabular}

\section{Keywords:}

Benchmark test functions Computational methods Metaheuristic algorithms Particle swarm optimisation Solar panels Tilt angle

\begin{abstract}
This paper presents an intelligent computational method using the PSO (particle swarm optimisation) algorithm to determine the optimum tilt angle of solar panels in PV systems. The objective of the paper is to assess the performance of this method against conventional methods of determining the optimum tilt angle. The method presented here can be used to determine the optimum tilt angle at any location around the world. In this paper, it was applied to Brunei Darussalam, and succeeded in computing monthly optimum tilt angles, ranging from $34.7^{\circ}$ in December to $-26.7^{\circ}$ in September. Results showed that changing the tilt angle every month, as determined by the PSO algorithm, increased annual yield by: (i) $5.94 \%$, compared to keeping it fixed at $0^{\circ}$, (ii) $8.65 \%$, compared to Lunde's method and (iii) $17.31 \%$, compared to Duffie and Beckman's method. Benchmark test functions were used to compare and evaluate the performance of the PSO algorithm with the artificial bee colony ( $\mathrm{ABC})$ algorithm, another metaheuristic algorithm. The tests revealed that the PSO algorithm outperformed the $\mathrm{ABC}$ algorithm, exhibiting lower root mean square error and standard deviation, better convergence to the global minimum, more accurate location of the global minimum, and faster execution times.
\end{abstract}

This is an open access article under the CC BY-SA license.

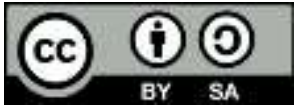

\section{Corresponding Author:}

Namruta S. Kanianthara

Electrical and Electronic Engineering Programme Area

Universiti Teknologi Brunei

Jalan Tungku Link, Gadong, BE1410, Bandar Seri Begawan, Brunei Darussalam

Email: namruta.kanianthara@hotmail.com

\section{INTRODUCTION}

Dwindling reserves of fossil fuels, environmental concerns relating to the impact of our carbon footprint on the Earth, and the global increase in energy demand have spurred a growing interest in using renewable energy resources for electricity generation. In particular, investment in solar panel technology has attracted a majority of the attention as a promising candidate in supplying a greener future. Naturally, with this comes developments in the industry to efficiently harness solar energy, and increase the amount of solar radiation that a photovoltaic (PV) system can yield.

The tilt angle of a solar panel plays an important role in determining the annual yield, and therefore the overall performance, of a PV system. The amount of solar radiation incident on a panel is maximised when the panel is tilted in such a way that the Sun's rays arrive perpendicularly to the panel. Therefore, there exists a significant benefit in determining the tilt angle at which the solar radiation yield is highest; this is known as the optimum tilt angle. The optimum tilt angle depends on the latitude of the location and its climate data; thus, the determination of this value requires solar radiation data for that site. 
Existing literature has hitherto suggested various non-computational methods to determine the optimum tilt angle $\beta_{\text {opt }}$ at any latitude $\phi$. Duffie and Beckman [1] recommend $\beta_{\text {opt }}=\left(\phi+15^{\circ}\right) \pm 15^{\circ}$, while Lunde [2] proposed $\beta_{\text {opt }}=\phi \pm 15^{\circ}$. Here, the plus sign is used for locations in the northern hemisphere, while the minus sign is used for locations in the southern hemisphere.

Numerous authors have calculated optimum tilt angles for locations around the world by conducting mathematical procedures based on solar radiation data. Tang and $\mathrm{Wu}$ [3] estimated monthly optimum tilt angles in 152 south-facing locations around China by using estimations of monthly diffuse radiation to calculate the annual radiation for a particular tilt angle, and repeating for different tilt angles until a maximum was reached. Yang and Lu [4] considered hourly solar radiation, solved using Orgill and Hollands hourly diffuse ratio [5], to arrive at an annual optimum tilt angle in Hong Kong of $20^{\circ}$. Morad et al. [6] used an equation solver programme to find monthly optimum tilt angles for PV modules in three cities across Iraq, which varied from $10^{\circ}$ in June to $56^{\circ}$ in January and December. The annual optimum tilt angle was $31^{\circ}$ for all cities. Bakirci [7] used correlations between solar radiation and tilt angle to estimate the average daily solar radiation incident on a tilted surface. The author manually searched for values of tilt angle which returned the highest solar radiation for a particular month. The monthly tilt angles ranged from $0^{\circ}$ to $65^{\circ}$ and resulted in $13 \%$ to $22 \%$ increases in yearly solar energy yield in eight provinces across Turkey. Heywood [8] derived equations to calculate optimum tilt angles for latitudes in South Africa. Asowata et al. [9] validated these equations for their PV setup in Vanderbijlpark, South Africa, arriving at tilt angles of $16^{\circ}, 26^{\circ}$, and $36^{\circ}$, the latter two of which yielded higher solar radiation. Ekpenyong et al. [10] developed a polynomial model to determine an optimum tilt angle for winter seasons in Akwa, Nigeria. The model generated a value of $24.7^{\circ}$. Handoyo et al. [11] derived monthly optimum tilt angles in Surabaya, Indonesia from calculations of the angle of incidence of beam radiation on a solar collector. The optimum tilt angle varied from $0^{\circ}$ to $40^{\circ}$ from March to September (north-facing), and from $0^{\circ}$ to $30^{\circ}$ (south-facing) from October to February. Hussein et al. [12] undertook a theoretical investigation into the performance of PV modules in Cairo, Egypt by predicting their annual performance on Fortran software integrated with the TRNSYS (transient system) simulation tool. Optimum tilt angles for each month varied from $20^{\circ}$ to $30^{\circ}$, with horizontal modules yielding $95 \%$ of the maximum output energy, compared to vertical modules yielding $41 \%$.

Several studies report increases in the annual yield of PV systems when monthly optimum tilt angles are used, compared to when annual optimum tilt angles are used. Monthly optimum tilt angles for a solar collector in Brunei Darussalam have been calculated by Yakup and Malik [13]; they conducted a manual search of values of tilt angle for which the annual solar radiation was the highest. The monthly optimum tilt angles varied from $1.6^{\circ}$ to $32.3^{\circ}$. Changing the tilt angle every month resulted in a $4.46 \%$ increase in annual solar radiation, compared to when the panel was fixed at $0^{\circ}$. It also resulted in a higher annual yield when compared to changing the tilt angle four times a year (3.9\% increase) and keeping the tilt angle fixed at an annual tilt angle of $3.3^{\circ}$ (4.4\% increase). Jamil et al. [14] determined optimum tilt angles for Aligarh and New Delhi in India. In Aligarh, the gains in annual solar radiation were $12.92 \%, 11.61 \%$, and $6.51 \%$, when monthly, seasonal, and annual optimum tilt angles were used respectively, compared to a horizontal surface. In Delhi, the same gains were $13.13 \%, 11.80 \%$, and $7.58 \%$. Herrera-Romero et al. [15] studied the optimum tilt angle adjustment frequency for solar collectors in Veracruz, Mexico. In terms of annual energy gain, changing the tilt angle monthly (ranging from $41.24^{\circ}$ to $-4.94^{\circ}$ ) was the best scenario over daily, fortnightly, monthly, seasonally, bi-annually, and yearly adjustments. Although daily adjustments collected the maximum energy, the economical strain of this method deemed it impractical. Ullah et al. [16] found that in Lahore, Pakistan, changing the tilt angle daily, monthly, seasonally, and biannually increased energy yield by $7.41 \%, 7.25 \%, 6.09 \%$, and $5.90 \%$, respectively, compared to keeping it at an annual fixed angle of $31.5^{\circ}$.

Relationships made between latitude and optimum tilt angle are common. Lewis [17] obtained optimum tilt angles of four locations in Alabama, USA, and applied a linear regression analysis to recommend that the optimum tilt angle should be $\phi \pm 8^{\circ}$. Gopinathan [18] measured the annual radiation in Lesotho, South Africa, for different methods of obtaining tilt angle, including Duffie and Beckman's [1]. The maximum annual radiation was reached when $\beta_{\text {opt }}=\phi$ for azimuth angles $<150^{\circ}$, and $\beta_{\text {opt }}=\phi-15^{\circ}$ for high azimuth angles. Meanwhile, many authors have found that the calculated annual optimum tilt angle is similar to the latitude of the location. Jafarkazemi and Saadabadi [19] found that in Abu Dhabi, UAE, the yearly optimum tilt angle was $22^{\circ}$, close to Abu Dhabi's latitude of $24.4^{\circ}$. Benghamen [20] found that the yearly optimum tilt angle for a site in Madinah, Saudi Arabia $\left(\phi=24.5^{\circ}\right)$, was $23.5^{\circ}$. However, using the yearly optimum tilt angle resulted in an $8 \%$ loss in energy compared with using monthly optimum tilt angles. Pour et al. [21] computed the yearly optimum tilt angle for a location in Isfahan, Iran $\left(\phi=32^{\circ}\right)$ to be $28.84^{\circ}$, as well as monthly optimum tilt angles varying from $0.15^{\circ}$ to $57.74^{\circ}$. The annual solar radiation with optimum monthly, seasonal, and yearly tilt angles increased by $14.1 \%, 12.8 \%$, and $7.1 \%$, respectively, compared to a flat surface. Jamil et al. [14] calculated annual optimum tilt angles of $27.62^{\circ}$ for Aligarh $\left(\phi=27.89^{\circ}\right)$ and $27.95^{\circ}$ for New Delhi $\left(\phi=28.61^{\circ}\right)$. Energy losses were $5.68 \%$ in Aligarh and $4.91 \%$ in New Delhi with 
annual optimum tilt angles compared to monthly optimum tilt angles. Yakup and Malik [13], Morad [6], Herrera-Romero et al. [15], and Ullah [16] also reported annual optimum tilt angles which are similar to the latitudes of their respective locations. Nevertheless, the method of setting the tilt angle equal to the latitude is not suitable for all locations, as some experience weather that is cloudier in winter than in summer, or the Sun's position in the sky throughout the year spans a wider path than other locations. Therefore, there warrants a need for monthly optimum tilt angles to be computed.

The employment of metaheuristic optimization algorithms to determine the optimum tilt angle of solar panels serve to speed up the search process of finding a solution and to improve the accuracy of the solution. The harmony search (HS) metaheuristic algorithm has been applied by Mian et al. [22] to obtain the optimum tilt angle of solar panels in six stations across China. Dixit et al. [23] compared the performance of the particle swarm optimization (PSO) algorithm with the artificial neural network (ANN) estimator in determining the annual optimum tilt angles for cities around India, concluding that for applications where accurate solar radiation data may not be available, PSO can be more effective than ANN. The genetic algorithm (GA) and the simulated-annealing (SA) method have been used by Chen et al. [24] to optimise the tilt angle of fixed solar panels for different areas in Taiwan. While experimental results indicated that the measured monthly tilt angles were very close to simulated results, other applications have revealed the limitations of GA and SA in terms of convergence speed and accuracy of the solution. Chang [25] incorporated the orthogonal arrays (OA) technique into the ant direction hybrid differential evolution (ADHDE) technique to form a new heuristic ADHDEOA method to determine the annual tilt angle for PV modules across seven areas in Taiwan. The method reduced the search space of the problem and results indicated that the measured annual tilt angles were similar to the simulation results. For the same areas in Taiwan, Chang [26], [27] optimised the tilt angles using the PSO method with nonlinear time-varying evolution (PSO-NTVE) to maximise the electrical energy from the modules. The results confirmed that a tilt angle of $23.5^{\circ}$ is not suitable for all regions of Taiwan, and should vary with location. Tabet et al. [28] found the optimum tilt angle of a photovoltaic-thermal solar collector in Algeria by calculating the solar radiation on a tilted surface and applying the PSO method. The results indicated that the tilt angle should be changed throughout the year to yield maximum efficiency. The annual solar radiation increased when the optimised tilt angles were used.

While the non-computational methods described above provide very good estimations of optimum tilt angles in their respective locations, their accuracy could perhaps be improved. Not all consider the potential benefit of varying the tilt angle throughout the year to attain the highest possible annual yield. Those that do, employ manual means of searching for tilt angles which yield the highest radiation, which may overlook the true optimum tilt angle. The determination of the optimum tilt angle can also be constructed as an optimization problem, which can be solved by meta-heuristic algorithms. Various studies have illustrated the benefit of employing such algorithms to obtain the optimum tilt angle, as they are capable of quickly finding the best solution among all solutions. The studies have reported increases in annual yield when meta-heuristic algorithms are used. Still, a consensus has not yet appeared to have been reached among existing literature on how best to accurately determine the optimum tilt angle for a particular location throughout the year.

This paper presents the use of particle swarm optimization (PSO) to optimise the tilt angle of solar panels for each month of the year. The method aims to be potentially more accurate and yield higher values of solar radiation than existing methods. The method is applied to a latitude of $4.97^{\circ}$ in Brunei Darussalam to compare the annual yield obtained using this method with that obtained through manual means by a previous study in Brunei Darussalam; however, the method is expected to be suitable for any latitude. Originally developed by Kennedy and Eberhart [29], [30], the PSO algorithm has seen various developments and improvements in performance since its inception, the prominent ones of which are implemented in this paper. The paper is organised as follows: the next section describes the methodology and implementation of the PSO algorithm to determine the optimum tilt angle. The relationship between tilt angle and solar radiation is established and the PSO algorithm is explained. Following are discussions of parameters used, coupled with a brief review of the developments in the algorithm. The improved algorithm is then implemented for a latitude of $4.97^{\circ}$ in Brunei Darussalam. Finally, the performance of the PSO algorithm is evaluated by conducting a comparative analysis between the PSO algorithm and the ABC algorithm using benchmark test functions. The results are presented to illustrate the benefits of deploying the algorithm for this purpose, compared to conventional methods of obtaining optimum tilt angle.

At present, there is no single method, value, or algorithm to accurately determine the optimum tilt angle that is widely accepted by researchers. Therefore, it is important to note that while this paper does explore, to the authors' current best knowledge, a contemporary means to find the optimum tilt angle for each month, it does not provide a definitive answer; rather, it may spark some interest in the importance of such an angle in PV applications, and the benefit of using particle swarm optimization to change it every month. At 
the very least, it is hoped that this paper contributes to the increasing pool of knowledge and understanding surrounding optimum tilt angles, and perhaps inspire fellow researchers to further explore and develop the method discussed here for their own applications.

\section{METHODOLOGY AND IMPLEMENTATION OF PARTICLE SWARM OPTIMISATION (PSO) ALGORITHM}

2.1. Calculation of daily solar radiation on a tilted surface

For the PSO algorithm to determine the optimum tilt angle, $\beta_{\text {opt }}$, of a solar panel, the daily radiation incident on a tilted surface for the average day of each month, $H(\beta)$, must be calculated. The goal of the algorithm is to search for the values of tilt angle $\beta$ which yield the highest $H(\beta)$. The calculation of $H(\beta)$ will form the objective function of the PSO algorithm.

An estimation for the daily radiation on a tilted surface for the average day of each month, $H(\beta)$, have been proposed by numerous authors. In particular, the relationships and equations developed by Liu and Jordan [31], [32] are widely reputed and have been reviewed by Klein [33]. The method is described here. Liu and Jordan [31] proposed that the average daily radiation on a horizontal surface, $H$, for each month, can be expressed by defining $K_{T}$, the clearness index, or the fraction of the average daily extra-terrestrial radiation, $H_{O h}$, for each month,

$$
K_{T}=\frac{H}{H_{0 h}}
$$

$H$ is obtained from NASA's power data access viewer tool for the period 01/01/2015 to 30/09/2019, and latitude $4.97^{\circ}$ for Brunei Darussalam [34]. $H_{0 h}$ is characterized by the following equation:

$$
H_{0 h}=\frac{24}{\pi} I_{S C}\left[1+0.034 \cos \left(2 \pi \frac{n}{365.24}\right)\right] \times\left(\cos \phi \cos \delta \sin \omega_{s}+\omega_{s} \sin \phi \sin \delta\right)
$$

Here, $I_{s c}$ is the solar constant (equal to $1367 \mathrm{Wm}^{-2}$ ), $n$ is the day number of the year (average day of each month), $\phi$ is the latitude, $\delta$ is the solar declination, which can be expressed as,

$$
\delta=\frac{\pi}{180} 23.45 \sin \left[360\left(\frac{284+n}{365}\right)\right],
$$

and $\omega_{s}$ is the sunset hour angle, which can be expressed as,

$$
\cos \omega_{s}=-\tan \phi \tan \delta
$$

All angles are in radians. The average daily radiation on a tilted surface, $H(\beta)$, can thus be expressed as:

$$
(\beta)=R H
$$

$R$ is the ratio of daily average radiation on a tilted surface to that on a horizontal surface for each month. It is estimated by individually considering the beam, diffuse, and reflected components of the radiation incident on a tilted surface. Assuming the diffuse and reflected radiation to be isotropic, Liu and Jordan [32] estimated that $R$ can be calculated as

$$
R=\left(1-\frac{D}{H}\right) R_{B}+\left(\frac{1+\cos \beta}{2}\right) \frac{D}{H}+\frac{\rho(1-\cos \beta)}{2}
$$

where $D$ is the monthly average daily diffuse radiation on a horizontal surface, $R_{B}$ is the ratio of the average daily beam radiation on a tilted surface, $B(\beta)$, to that on a horizontal surface, $B$, for each month. $\beta$ is the tilt angle from the horizontal, and $\rho$ is the albedo, equal to 0.2 on Earth. In (6), the first term is the monthly average daily beam radiation incident on a tilted surface, the second is the monthly average daily diffuse radiation on a tilted surface, and the third is the monthly average daily reflected radiation on a tilted surface.

As surmised by Klein [33], Liu and Jordan suggested that $R_{B}$ is equivalent to the ratio of average daily extra-terrestrial radiation on a tilted surface, $H_{0}(\beta)$, to that on a horizontal surface, $H_{0 h}$, for each month,

$$
R_{B}=\frac{B(\beta)}{B}=\frac{H_{0}(\beta)}{H_{0 h}}
$$

They recommend that for surfaces facing the equator, $R_{B}$ can be estimated as, 


$$
R_{B}=\frac{\cos (\phi-\beta) \cos \delta \sin \omega_{s^{\prime}}+\omega_{s^{\prime}} \sin (\phi-\beta) \sin \delta}{\left(\cos \phi \cos \delta \sin \omega_{s}+\omega_{s} \sin \phi \sin \delta\right)}
$$

where $\omega_{s}$, is the sunset hour angle for a tilted surface, given by"

$$
\omega_{s^{\prime}}=\min \left\{\omega_{s}, \arccos [-\tan (\phi-\beta) \tan \delta]\right\}
$$

Measurements of $D$ are seldom available, so it must be estimated from values of $H$. Several authors have found that the ratio $D / H$ (diffuse radiation fraction) is a function of $K_{T}$. Liu and Jordan [31] proposed that:

$$
\frac{D}{H}=1.390-4.027 K_{T}+5.531{K_{T}}^{2}-3.108 K_{T}{ }^{3}
$$

Page [35] alternatively proposed that:

$$
\frac{D}{H}=1.00-1.13 K_{T}
$$

According to Klein [33], Page's relationship results in a more accurate estimation of $D / H$ when compared with measurements reported by Choudhury [36], Stanhill [37], and Norris [38]. However, Klein observed that values of $R$ estimated from (6) tend to agree more closely with experimental measurements when the Liu and Jordan relationship is used. Therefore, in this paper, (9) is chosen.

Thus, the total average daily solar radiation incident on a tilted panel, $H(\beta)$, can be calculated for each month by substituting (7) and (9) into (6), and then substituting (6) into (5). It must be noted that since this paper aims to develop an algorithm to find a value for $\beta$ which is the optimum value $\beta_{\text {opt }}$, a known value of $\beta$ is not actually placed into (6); rather, $\beta$ forms the unknown decision variable to be optimised in the PSO algorithm, as explained later in 2.2.

\subsection{Particle swarm optimisation (PSO) algorithm}

Now that $H(\beta)$ can be calculated, the equations above can be put into the PSO algorithm (5) is the objective function to be optimised. Background and an explanation of the algorithm follow, providing an understanding of how it arrives at an optimum angle $\beta_{\text {opt }}$ for each month. Particle swarm optimization (PSO) is a population-based stochastic optimization technique developed by Eberhart and Kennedy [29], [30]. Inspired by swarm intelligence observed in nature, such as birds flocking, fish schooling, and bee swarming, the algorithm was introduced as an evolutionary computation method to simulate social behaviour in swarms. Members of a swarm cooperate to find food by learning from their previous experience and the experience of other members. It is this behaviour which PSO emulates. Akin to other population-based optimization techniques, PSO optimises a problem by iteratively improving the current best solution according to a measure of 'fitness', until the optimum of the function is reached. The true strength of the algorithm stems from the interaction of the particles as they collaboratively explore the search space. The steps in the PSO algorithm are outlined in a flowchart, as in Figure 1.

PSO embraces a simple concept which can be executed in just a few lines of code. The mathematics involved is basic, and the computational prowess it calls for is minimal, as memory and speed requirements are low; thus, it is inexpensive to implement. While the original mathematical model of the motion of particles in PSO developed by Eberhart and Kennedy [29], [30] made great strides in the field of evolutionary computation in swarm intelligence, attempts to improve its performance have since appeared. Shi and Eberhart [39] introduced inertia weight, $\omega$, in the range [0.9, 1.2] into the model to attain balance between local exploitation and global exploration. Performance was further enhanced by Clerc and Kennedy [40], who removed the need for $\omega$ to be specified and instead introduced a constriction factor, $\chi$, to ensure convergence of particles, leading to the equation.

$$
\begin{aligned}
& v_{i j}(t+1)=\chi\left[v_{i j}(t)+r_{1} \varphi_{1}\left(p_{i j}(t)-x_{i j}(t)\right)+r_{2} \varphi_{2}\left(g_{j}(t)-x_{i j}(t)\right)\right] \\
& \mathrm{x}_{\mathrm{ij}}(\mathrm{t}+1)=\mathrm{x}_{\mathrm{ij}}(\mathrm{t})+\mathrm{v}_{\mathrm{ij}}(\mathrm{t}+1)
\end{aligned}
$$

The constriction factor $\chi$ is defined as,

$$
\chi=\frac{2 \kappa}{\left|2-\varphi-\sqrt{\varphi^{2}-4 \varphi}\right|}
$$

where $\varphi=\varphi_{1}+\varphi_{2}$ and $\varphi \geq 4$. $\varphi$ is commonly set to 4.1, and $\varphi_{1}$ and $\varphi_{2}$ are typically equal, so that $\varphi_{1}=\varphi_{2}=$ 2.05. $\kappa$ is defined as $\kappa \in[0,1]$, and is commonly set to 1 . Thus $\chi=0.7298$. Thus, according to Clerc and 
Kennedy, the ideal setting for a PSO algorithm with inertia is $\omega=\chi=0.7298$. Using their constriction coefficients allow a fixed value of $\omega$ to be used, instead of choosing a value in the range $[0.9,1.2]$.

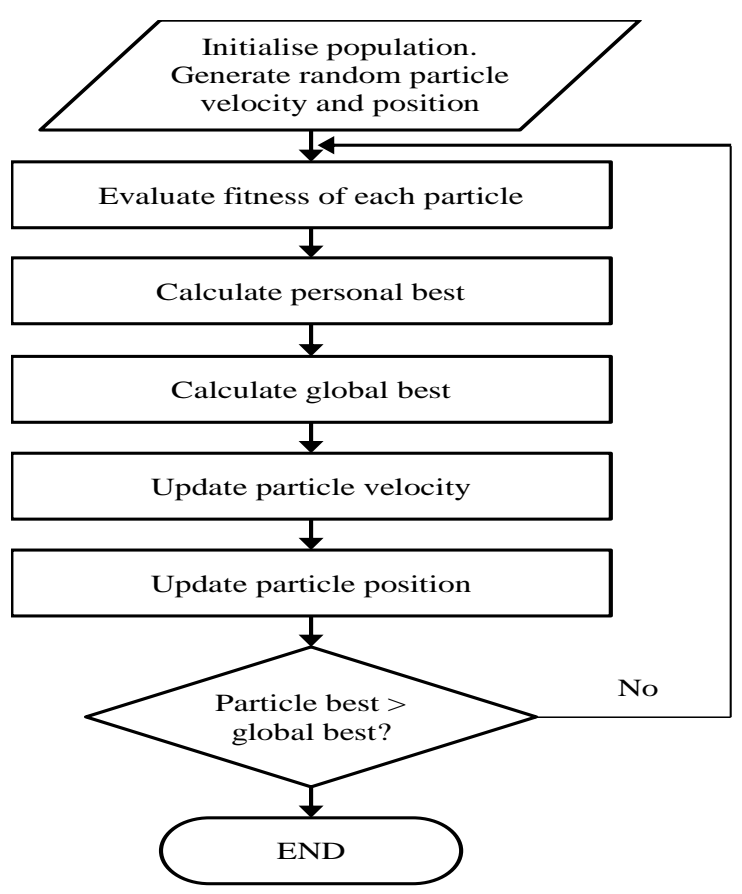

Figure 1. Flowchart illustrating outline of PSO algorithm

To implement the PSO algorithm for this application, the objective function of the problem must be specified. This is the monthly average daily solar radiation incident on a tilted panel, $H(\beta)$, as defined by (5). The purpose of the algorithm is to find the optimum tilt angle $\beta_{\text {opt }}$ for each month, which occurs when $H(\beta)$ is the highest i.e., the maximum of the function. Therefore, this is a maximizing PSO algorithm. The problem can now be defined. The decision variable is the tilt angle $\beta$; thus, the number of decision variables is 1 . The search space is bound by a set of limits; the lower and upper bounds of the decision variable. These are set to $-45^{\circ}$ and $45^{\circ}$ respectively; this amply covers the range of possible angles that $\beta$ could be. The parameters of the PSO algorithm can now be defined. The constriction coefficients are selected as above. The maximum number of iterations is set to 100 , and the population (swarm) size is 20; over trial and error, these values have been deemed sufficient to run the algorithm successfully. The particles' velocities are clamped to a maximum velocity $v_{\max }$ to control their search ability so that they do not accelerate beyond the search space. If $v_{\max }$ is too small, particles may not have enough acceleration to sufficiently explore and move far enough beyond local minima; they may fail to reach better solutions. If $v_{\max }$ is too high, particles may accelerate too quickly and miss good solutions. It is equal to the range of the decision variable, and is typically set to 10 to $20 \%$ of this range [41]. The parameters selected for the PSO algorithm using Clerc and Kennedy's constriction coefficients are listed in Table 1.

Apt selection of $\varphi_{1}$ and $\varphi_{2}, \chi$ (or $\omega$ ), and $v_{\max }$ can provide a balance between local search and global search, better convergence, a fewer number of iterations, and less time. Now that the problem is defined, the constriction coefficients set, and the parameters chosen, the algorithm is ready to perform the optimization.

Table 1. Parameters selected for PSO algorithm using clerc and kennedy's constriction coefficients

\begin{tabular}{cc}
\hline Parameters & \\
$\varphi_{I}=\varphi_{2}$ & 2.05 \\
$\chi(=\omega)$ & 0.7298 \\
$v_{\max }$ & $0.2 *($ VarMax - VarMin) \\
Maximum number of iterations (MaxIt) & 100 \\
Population (swarm) size & 20 \\
Lower bound of decision variable (VarMin) & $-45^{\circ}$ \\
Upper bound of decision variable (VarMax) & $45^{\circ}$ \\
\hline
\end{tabular}




\section{RESULTS AND DISCUSSION}

\subsection{Obtaining optimum tilt angles from the PSO algorithm}

The PSO algorithm is run for each month to generate twelve values of optimum tilt angle $\beta_{\text {opt }}$. The objective function (5) has three inputs: the monthly average daily irradiation for each month $H$, the average day number of the month $n$, and the latitude $\phi$. Once a run completes, the best cost of the swarm and the best position at the best cost are recorded. These two solutions are the monthly average daily radiation on a tilted surface $H(\beta)$ and the corresponding optimum tilt angle $\beta_{\text {opt }}$, respectively. The results are shown in Table 2 .

Table 2 . Average daily radiation on a tilted surface $H(\beta)$ and optimum tilt angle $\beta_{\text {opt }}$, as solved by PSO algorithm

\begin{tabular}{|c|c|c|c|c|c|}
\hline & \multirow[t]{2}{*}{$\begin{array}{l}\text { Average day } \\
\text { number, } n\end{array}$} & \multirow{2}{*}{$\begin{array}{c}\text { Average daily radiation, } \\
\text { horizontal surface, } H \text { (NASA) } \\
\text { Whm }^{-2 \text { day-1 }}\end{array}$} & \multirow{2}{*}{$\begin{array}{c}\text { Average daily radiation, } \\
\text { tilted surface, } H(\beta) \\
\mathrm{Whm}^{-2 \text { day-1 }}\end{array}$} & \multicolumn{2}{|c|}{ Optimum tilt angle, $\beta_{o p t}$} \\
\hline & & & & $\mathrm{rad}$ & $\mathbf{o}$ \\
\hline January & 17 & 4816.69 & 5444.25 & 0.5617 & 32.1830 \\
\hline March & 75 & 5541.63 & 5580.60 & 0.1378 & 7.8954 \\
\hline April & 105 & 5655.40 & 5704.92 & -0.1546 & -8.8579 \\
\hline May & 135 & 5382.62 & 5676.40 & -0.3753 & -21.5031 \\
\hline July & 198 & 5264.97 & 5646.36 & -0.4288 & -24.5684 \\
\hline August & 228 & 5376.01 & 5500.97 & -0.2498 & -14.3125 \\
\hline September & 258 & 5253.32 & 5254.00 & 0.0231 & 1.3235 \\
\hline October & 288 & 5019.31 & 5192.35 & 0.3051 & 17.4809 \\
\hline November & 318 & 4958.86 & 5507.35 & 0.5215 & 29.8797 \\
\hline December & 344 & 4688.16 & 5415.08 & 0.6059 & 34.7155 \\
\hline
\end{tabular}

The highest average daily radiation on a tilted surface occurs in April at $5705 \mathrm{Whm}^{-2} \mathrm{day}^{-1}$, while October receives the lowest at $5192 \mathrm{Whm}^{-2} \mathrm{day}^{-1}$. This correlates with the climate in Brunei Darussalam; April and May are typically the warmest months and experience the most hours of sunshine per day, and the most rainfall is seen from October to December. Figure 2 illustrates more clearly the variation in $\beta_{\text {opt }}$ throughout the year. $\beta_{\text {opt }}$ varies from $34.7^{\circ}$ in December to $1.3^{\circ}$ in September, and from $-26.7^{\circ}$ in June to $8.9^{\circ}$ in April. From April to August, $\beta_{\text {opt }}$ is negative; this indicates that the solar panel should be orientated to face north. This is because at this site (and those on similar latitudes), the annual sun path area covers both the northern and southern hemispheres, crossing the Equator from April to August so that for a panel to be perpendicular to the Sun's rays during these months, it should face north to capture the most radiation.

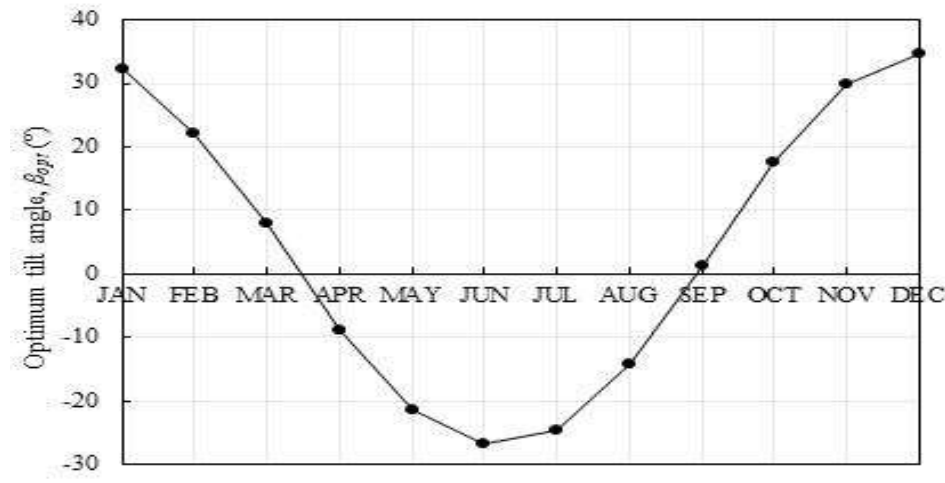

Figure 2. Variation in optimum tilt angle $\beta_{\text {opt }}$ throughout the year, as solved by the PSO algorithm

The values of $\beta_{\text {opt }}$ are in agreement with those obtained by Yakup and Malik [13] for a solar collector in Brunei Darussalam. The monthly $\beta$ values are averaged to find a value for annual $\beta_{\text {opt }}$. The result is $4.14^{\circ}$, which is comparable to Yakup and Malik's value of 3.39 ${ }^{\circ}$. This agrees with findings made by numerous authors [6], [14][16], [19]-[21] that the annual $\beta_{\text {opt }}$ is similar to the latitude $\left(\phi=4.97^{\circ}\right.$ in Brunei Darussalam). 


\subsection{Comparison of annual solar radiation using tilt angles solved by PSO with those solved by other} means

To assess the PSO algorithm's performance in providing values of $\beta_{\text {opt }}$ which yield the highest solar radiation on a tilted surface each month, the values of $\beta_{\text {opt }}$ are compared with those solved by other means. The annual $H(\beta)$ values obtained using each method are compared. First, the annual $H(\beta)$ is compared with the annual $H(\beta)$ obtained when using the annual $\beta_{\text {opt }}$ of $4.14^{\circ}$. The calculations in 2.1 which compute monthly $H(\beta)$ are performed with $\beta=4.14^{\circ}$ for all months. A comparison of annual $H(\beta)$ is also made with when $\beta_{\text {opt }}$ is fixed at $0^{\circ}$ i.e., when the panel is flat. The latter is equivalent to the average daily radiation on a horizontal surface i.e., $H$, as in Table 2 . The results are presented in Table 3.

Table 3. Monthly average daily radiation on a tilted surface $H(\beta)$ using: monthly $\beta_{\text {opt }}$ solved by PSO, fixed

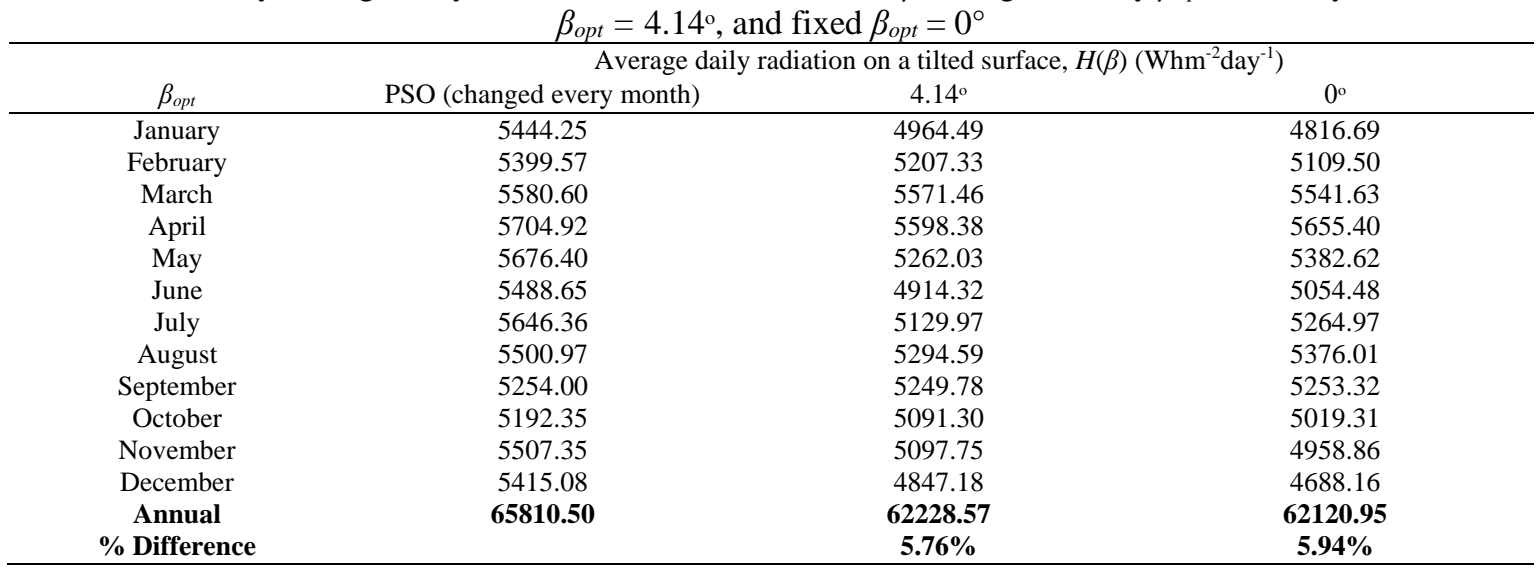

Table 3 shows that changing $\beta_{\text {opt }}$ every month as solved by the PSO algorithm yields $65,811 \mathrm{Whm}^{-}$ ${ }^{2}$ day $^{-1}$ annual $H(\beta)$ while keeping it fixed at $4.14^{\circ}$ yields $62,229 \mathrm{Whm}^{-2} \mathrm{day}^{-1}$. This is an increase of $5.76 \%$. Fixing $\beta_{\text {opt }}$ at $0^{\circ}$ yields $62,121 \mathrm{Whm}^{-2} \mathrm{day}^{-1}$; the increase in annual $H(\beta)$ on this is $5.94 \%$. From these results alone, it appears it is more beneficial to change $\beta_{\text {opt }}$ every month; this is encouraging, as it provides evidence that the algorithm has succeeded in determining monthly optimum tilt angles.

Next, two conventional methods are considered. Duffie and Beckman [1] suggest that $\beta_{\text {opt }}=\left(\phi+15^{\circ}\right) \pm$ $15^{\circ}$, while Lunde [2] proposed that $\beta_{\text {opt }}=\phi \pm 15^{\circ}$. The plus and minus signs are for locations in the northern and southern hemispheres, respectively. Table 4 shows the values of $H(\beta)$ when $\beta_{\text {opt }}=\phi+15^{\circ}=19.98^{\circ}$ and when $\beta_{\text {opt }}=$ $\left(\phi+15^{\circ}\right)+15^{\circ}=34.97^{\circ}$. Both methods yield lower annual $H(\beta)$ than when the PSO algorithm is used to determine $\beta_{\text {opt. }}$ The algorithm results in $8.65 \%$ higher annual $H(\beta)$ than Lunde's method, and $17.31 \%$ higher annual $H(\beta)$ than Duffie and Beckman's method, evidencing that the algorithm finds better values of $\beta_{\text {opt }}$ than the two methods. The results in Table 3 and Table 4 further substantiate the PSO algorithm's success in determining $\beta_{\text {opt }}$ for each month that yield maximum potential $H(\beta)$. It can, therefore, be posited with reasonable confidence that the PSO algorithm developed in this paper has the capability to increase the annual yield of a PV system set-up in Brunei Darussalam, and potentially in other locations around the world.

Figure 3 depicts how $H(\beta)$ is affected throughout the year using the different methods of obtaining $\beta_{\text {opt }}$. It illustrates more clearly the advantage of changing $\beta_{\text {opt }}$ every month as dictated by the PSO algorithm. The other methods yield generally lower $H(\beta)$ over the year. This may be because since these methods do not suggest changing $\beta$ every month, not all of the Sun's rays are incident on the panel every month. The largest discrepancies in $H(\beta)$ among the methods are seen from April to August - this is because the other methods do not generate negative values of $\beta_{\text {opt }}$ for these months. They overlook the fact that since Brunei Darussalam is located near the equator, its sun path lies in the northern hemisphere from April to August. This necessitates the need for $\beta_{o p t}$ to be negative, allowing the panel to be tilted optimally to receive the maximum solar radiation.

The effect of tilt angle $\beta$ on solar radiation on a tilted surface $H(\beta)$ throughout the year is shown in Figure 4. $\beta$ is manually changed from $-45^{\circ}$ to $45^{\circ}$ in increments of $5^{\circ}$, put into the equations in 2.1 , and the resulting $H(\beta)$ recorded for each month. Smaller increments of $\beta$ from $0^{\circ}$ to $5^{\circ}$ are input to hone in on the region where the optimum annual $\beta$ of $4.14^{\circ}$ lies. The $H(\beta)$ for every month at each $\beta$ is summed to get a corresponding annual $H(\beta)$. Thus, the effect of tilt angle on annual solar radiation is illustrated in Figure 5. 
Table 4. Monthly average radiation on a tilted surface $H(\beta)$ using monthly $\beta_{\text {opt }}$ solved by PSO, and using $\beta_{\text {opt }}$ solved by conventional methods

\begin{tabular}{cccc}
\hline & \multicolumn{2}{c}{ Average daily radiation on a tilted surface, $H(\beta)\left(\mathrm{Whm}^{-2}\right.$ day $\left.^{-1}\right)$} \\
$\beta_{\text {opt }}$ & Changed every month (PSO) & $\phi \pm 15^{\circ}=19.98^{\circ}$ & $\left(\phi+15^{\circ}\right) \pm 15^{\circ}=34.97^{\circ}$ \\
\hline January & 5444.2476 & 5351.5983 & 5439.0051 \\
February & 5399.5677 & 5397.4392 & 5300.3643 \\
March & 5580.5955 & 5490.1302 & 5134.2092 \\
April & 5704.9235 & 5192.2087 & 4557.5952 \\
May & 5676.3962 & 4642.7623 & 3864.0241 \\
June & 5488.6541 & 4243.2744 & 3453.2668 \\
July & 5646.3638 & 4466.0652 & 3663.5539 \\
August & 5500.9672 & 4813.1100 & 4138.2040 \\
September & 5254.0024 & 5056.4432 & 4623.1221 \\
October & 5192.3509 & 5189.0982 & 5018.9919 \\
November & 5507.3474 & 5445.7092 & 5490.8073 \\
December & 5415.0825 & 5280.8816 & $\mathbf{5 0 5 6 8 . 7 2 0 4}$ \\
Annual & $\mathbf{6 5 8 1 0 . 4 9 8 8}$ & $\mathbf{8 . 6 5 \%}$ & $\mathbf{5 6 0 9 8 . 3 6 1 4}$ \\
\% Difference & & $\mathbf{1 7 . 3 1 \%}$ \\
\hline
\end{tabular}

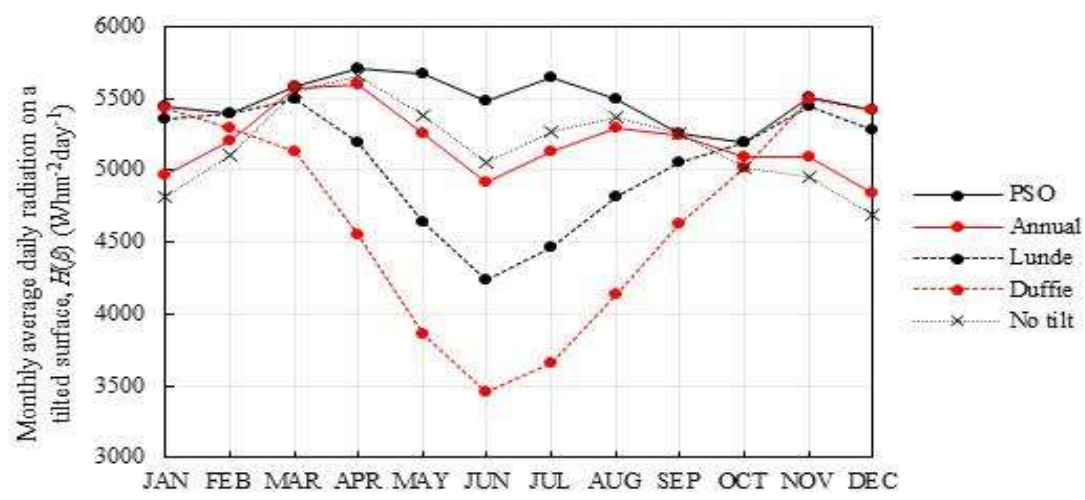

Figure 3. Monthly average daily radiation on a tilted surface $H(\beta)$ using different methods of obtaining optimum tilt angle $\beta_{\text {opt }}$

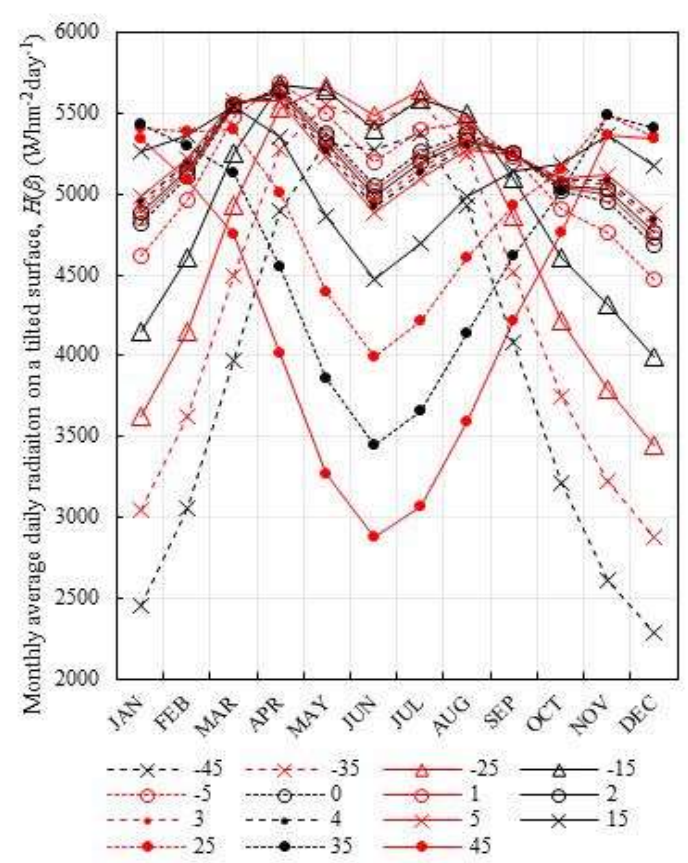

Figure 4. Effect of tilt angle $\beta$ on monthly average daily radiation on a tilted surface $H(\beta)$

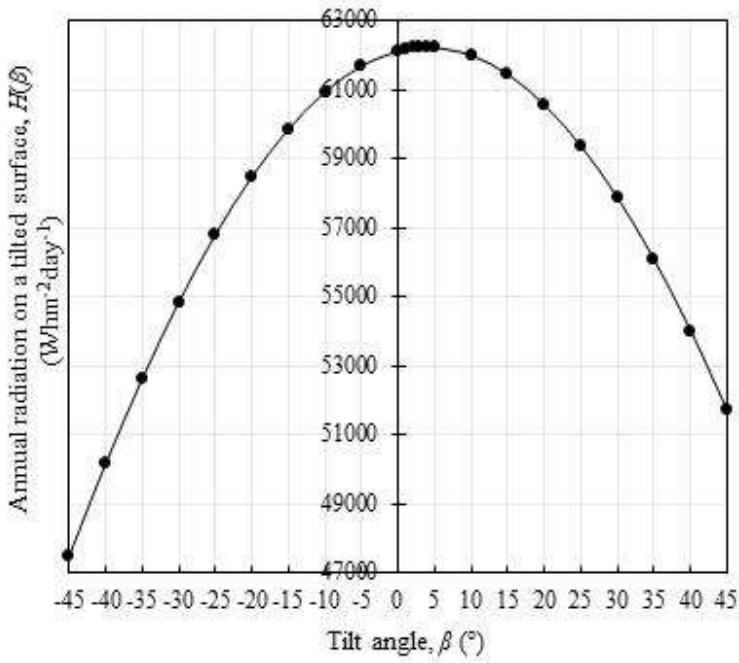

Figure 5. Effect of tilt angle $\beta$ on annual radiation on a tilted surface $H(\beta)$ 
It shows that if $\beta$ were to be fixed throughout the year, the highest annual $H(\beta)$ occurs when it is $4^{\circ}$. This is similar to the annual $\beta_{\text {opt }}$ of $4.14^{\circ}$. Although fixing $\beta$ at $4^{\circ}$ gives rise to the highest annual $H(\beta)$ compared to any other fixed value, Figure 4 shows that keeping it fixed at $4^{\circ}$ does not always yield the highest $H(\beta)$ for all months. In fact, keeping it fixed at any angle throughout the year is detrimental, as there are months (April to August), which suffer greatly when the $\beta$ is not changed. The graph demonstrates the effect and benefit of changing $\beta$ every month. It is also encouraging to learn that the highest values of $H(\beta)$ for each month correspond to values of $\beta$ which are very similar to those obtained by the PSO algorithm. Additionally, the highest annual $H(\beta)$ across all tilt angles from $-45^{\circ}$ to $45^{\circ}$ is $62,229 \mathrm{Whm}^{-2} \mathrm{day}^{-1}$, which corresponds to a value of $\beta=4^{\circ}$; this is very close to $4.14^{\circ}$ as determined by the PSO algorithm.

\subsection{Evaluating PSO algorithm's performance against data from a prior study in Brunei Darussalam}

To validate the effectiveness of the PSO algorithm against the same data set, the performance of the algorithm in obtaining values of $\beta_{\text {opt }}$ is evaluated against values of $\beta_{\text {opt }}$ obtained by Yakup and Malik [13] for Brunei Darussalam in 2000. Yakup and Malik calculated the monthly average daily radiation on a tilted surface, $H(\beta)$, using similar correlations described in 2.1 , but using average daily radiation on a horizontal surface $(H)$ data and average daily diffuse radiation on a horizontal surface $(D)$ data for the year 1992 from the Meteorological Department in Brunei Darussalam. $\beta_{\text {opt }}$ was found by inserting different values of $\beta$ into an equation like (5) and manually searching for the values of $\beta$ for which $H(\beta)$ was a maximum.

To conduct the evaluation, the values of $H$ from the 1992 data are entered into (5) ( $n$ and $\phi$ remain the same), and the algorithm run. As before, the algorithm generates $H(\beta)$ and the corresponding $\beta_{\text {opt }}$ for each month. The values of $H(\beta)$ are summed to get the annual $H(\beta)$. The results are tabulated in Table 5. It shows that the values of monthly $\beta_{\text {opt }}$ are very similar to those obtained using the $H$ data from NASA; it varies from $35.3^{\circ}$ in December to $1.4^{\circ}$ in September, and from $-26.1^{\circ}$ in June to $-8.8^{\circ}$ in April. The average annual tilt angle is $4.38^{\circ}$. Again, $\beta_{\text {opt }}$ is negative from April to August, indicating that the solar panel should face north during these months. The annual solar radiation $H(\beta)$ is $65,622 \mathrm{Whm}^{-2} \mathrm{day}^{-1}$ when the PSO algorithm is used to optimise tilt angles, and $61,986 \mathrm{Whm}^{-2} \mathrm{day}^{-1}$ on a horizontal surface i.e., no tilt. This is a $5.87 \%$ gain. This is greater than what Yakup and Malik had observed in their study; they reported a $4.46 \%$ gain in annual $H(\beta)$ compared to annual $H$. The superiority of the PSO algorithm in optimizing tilt angles is thus demonstrated here.

Table 5. Average daily radiation on a tilted surface $H(\beta)$ and optimum tilt angle $\beta_{\text {opt }}$ for each month, as solved by the PSO algorithm for 1992 Brunei Darussalam data, and average daily radiation on a tilted surface $H(\beta)$ for each month as determined by Yakup and Malik

\begin{tabular}{|c|c|c|c|c|c|}
\hline & $\begin{array}{l}\text { Average day } \\
\text { number, } n\end{array}$ & $\begin{array}{l}\text { Average daily radiation, } \\
\text { horizontal surface, } H \\
\text { (1992 Brunei data) }\end{array}$ & $\begin{array}{l}\text { Average daily radiation, } \\
\text { tilted surface, } H(\beta)\end{array}$ & \multicolumn{2}{|c|}{ Optimum tilt angle, $\beta_{\text {opt }}$} \\
\hline & & $\mathrm{Whm}^{-2}$ day $^{-1}$ & $\mathrm{Whm}^{-2}$ day $^{-1}$ & $\mathrm{rad}$ & o \\
\hline February & 47 & 5414.72 & 5740.47 & 0.3927 & 22.5001 \\
\hline March & 75 & 6117.22 & 6164.08 & 0.1425 & 8.1646 \\
\hline April & 105 & 5517.78 & 5565.34 & -0.1533 & -8.7834 \\
\hline June & 162 & 4706.67 & 5083.84 & -0.4554 & -26.0925 \\
\hline July & 198 & 4464.44 & 4737.98 & -0.4057 & -23.2449 \\
\hline August & 228 & 5304.72 & 5426.43 & -0.2487 & -14.2495 \\
\hline September & 258 & 5724.72 & 5725.91 & 0.0238 & 1.3636 \\
\hline October & 288 & 4777.22 & 4933.99 & 0.2998 & 17.1773 \\
\hline November & 318 & 4375.56 & 4802.12 & 0.5012 & 28.7166 \\
\hline
\end{tabular}

Figure 6 shows a comparison of $H(\beta)$ (using $H$ data from 1992) between the different means of obtaining $\beta_{\text {opt }}$ : the PSO algorithm, Yakup and Malik's results, and no tilt. The graph illustrates more clearly the higher gain in annual $H(\beta)$ compared to annual $H$ when the PSO algorithm is used, demonstrating the algorithm's advantage over the manual method of obtaining $\beta_{\text {opt }}$. 


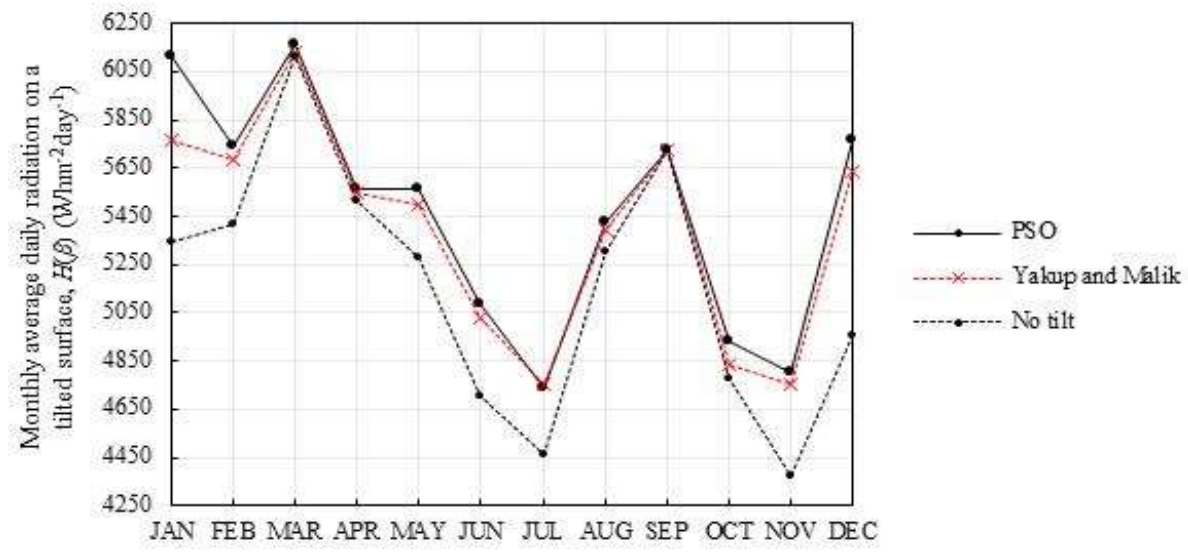

Figure 6. Monthly average daily radiation on a tilted surface $H(\beta)$ using different methods to obtain $\beta_{\text {opt }}$, based on 1992 data for Brunei Darussalam

\subsection{Performance comparison of PSO algorithm with artificial bee colony (ABC) algorithm using benchmark test functions}

Comparison of the PSO algorithm with another meta-heuristic algorithm can provide deeper insight into its performance. In the artificial bee colony $(\mathrm{ABC})$ algorithm, three groups of bees cooperate to find the best food source; the food sources represent the possible solutions to an optimization problem, while the best food source represents the location of the best solution. Similar to the PSO algorithm, the ABC algorithm optimizes a problem by iteratively searching for the current best solution according to a measure of 'fitness'and also a probabilistic selection.

Benchmark test functions are optimisation problems that are used to test the performance of optimization algorithms. They reveal characteristics such as exploration and exploitation abilities, robustness, and precision of the solution(s). Unimodal functions have one global minimum, and are thus easy to solve. Metaheuristic algorithms can be tested by these to evaluate local exploitation. Multimodal functions have many local minima and one global minimum. Algorithms would need to search the entire search space to locate the best solution, and so these functions test for global exploration. In this paper, six benchmark test functions are used to test and compare the PSO and ABC algorithms; their equations and properties are presented in Table 6. In the equations, $d$ is the number of dimensions in the problem; it is chosen to be 2 here. All six test functions are minimisation problems, and are optimised by the PSO and ABC algorithms. The global best, global best location, root mean square error (RMSE), standard deviation (SD), and execution time are calculated over 1000 trials for each test function and for the objective function (5); the results are shown in Table 7.

The results show that while the $\mathrm{ABC}$ algorithm solves the objective function and successfully finds the global best location, it is slower than the PSO algorithm, and exhibits higher errors in RMSE and SD. This indicates that there is less spread in the mean global solutions, and could speak for the robustness of the PSO algorithm. The results also reveal that the PSO algorithm performs better than the ABC algorithm in most of the benchmark tests. In all of the benchmark tests, the PSO algorithm arrives at a global best closer to zero than the $\mathrm{ABC}$ algorithm does. This suggests fast convergence towards the global best solution, and while this could indicate that the PSO algorithm converges too quickly on a local minimum and misses the global minimum, the location of the global best is more accurately found by it than by the $\mathrm{ABC}$ algorithm in all test functions. This demonstrates that the PSO algorithm does not converge prematurely, and has a good balance between global exploration and local exploitation, leading to higher quality of solutions.

The global best locations of the multimodal functions reveal that the $\mathrm{ABC}$ algorithm falls more easily into local minima and misses the global minimum. In particular, the algorithm gets trapped in local minima in the Griewank and Schwefel functions, as both are multimodal, and both have a large search domain with many sub-optimal locations. This implies that while the $\mathrm{ABC}$ algorithm may be good at local exploitation, it is poor at global exploration. This is evident in Figure 8, which shows MATLAB plots of the convergence of the PSO and ABC algorithms to the global best. For Ackley, Rastrigin, and Schwefel, it can be observed that the $\mathrm{ABC}$ algorithm tends to converge too soon, with the worst performance in global best being 9.797 for the Schwefel function.

While the lower RMSE and SD results achieved by the ABC algorithm for the unimodal Rosenbrock function (106.1114 and 105.6677, respectively), suggest that it is better at local exploitation than 
the PSO algorithm (RMSE $=121.5144, \mathrm{SD}=120.8452)$, it must be noted that RMSE and SD alone are not indicative of performance in this scenario; the global best of the Rosenbrock function is at $[1,1]$ for $d=2$; ABC finds the global best at [0.9111, 0.8344], while PSO finds it much closer at $[1.0048,1.0095]$. This overlooking of the global best solution and poor global exploration is evident in Figure 7(d), which once again shows early convergence of the ABC algorithm. The global minimum of the Rosenbrock function lies in a narrow valley; although easy to locate the valley, it is difficult to converge to the global minimum. The fact that the PSO algorithm converges to the global minimum so closely is telling of its good performance. Meanwhile, the same results for the unimodal Sphere function verify that the PSO algorithm is better at local exploitation than the ABC algorithm, as not only is its global best closer to zero (5.297E-10 compared to 0.0003 for $\mathrm{ABC}$ ), but its global best location of [-1.60E-05, 1.66E-05] is also closer to the actual global best location of $[0,0]$ for the Sphere function for $d=2$ (compared to [0.0068, -0.0151] for ABC). According to the results, the PSO algorithm also optimises all the test functions quicker than the ABC algorithm.

The comparison of performance using benchmark test functions illustrate the PSO algorithm's advantage over the ABC algorithm in this application. Exhibiting generally lower RMSE and SD, better convergence to the global best, higher accuracy of the global best locations, and faster execution time, it can be assured that the PSO algorithm is the superior choice in determining the optimum tilt angle $\beta_{\text {opt }}$.

Table 6. Benchmark test functions

\begin{tabular}{ccccc}
\hline Function & Equation & Search domain & Global minimum & Modality \\
\hline Ackley & $f(x)=20+e-\exp \left(-0.2 \sqrt{\frac{1}{d} \sum_{i=1}^{d} x_{i}^{2}}\right)-\exp \left(\sqrt{\frac{1}{d} \sum_{i=1}^{d} \cos \left(2 \pi x_{i}\right.}\right)$ & {$[-32,32]$} & $\mathrm{f}(0,0, \ldots, 0)=0$ & Multimodal \\
Griewank & $f(x)=\sum_{i=1}^{d} \frac{x_{i}^{2}}{4000}+1-\prod_{i=1}^{d} \cos \frac{x_{i}}{\sqrt{i}}$ & {$[-600,600]$} & $\mathrm{f}(0,0, \ldots, 0)=0$ & Multimodal \\
Rastrigin & $f(x)=10+\sum_{i=1}^{d}\left[x_{i}^{2}-10 \cos \left(2 \pi x_{i}\right)\right]$ & {$[-5.12,5.12]$} & $\mathrm{f}(0,0, \ldots, 0)=0$ & Multimodal \\
Schwefel & $f(x)=418.9829 d-\sum_{i=1}^{d}\left[x_{i} \sin \left(\sqrt{\left|x_{i}\right|}\right)\right]$ & {$[-500,500]$} & $\mathrm{f}(420.9687$, & M20.9687, \\
Rosenbrock & $f(x)=\sum_{i=1}^{d-1}\left[100\left(x_{i+1}-x_{i}^{2}\right)^{2}+\left(x_{i}-1\right)^{2}\right]$ & {$[-30,30]$} & $\mathrm{f}(1,1, \ldots, 1)=0$ & Unimodimodal \\
Sphere & $f(x)=\sum_{i=1}^{d} x_{i}^{2}$ & {$[-100,100]$} & $\mathrm{f}(0,0, \ldots, 0)=0$ & Unimodal \\
\hline
\end{tabular}

Table 7. Benchmark test functions and objective function (5) solved by PSO and ABC

\begin{tabular}{|c|c|c|c|c|c|c|}
\hline Test function & Algorithm & Global best & Global best location & RMSE & SD & Execution time \\
\hline \multirow{2}{*}{$\begin{array}{l}\text { Objective function } \\
\text { (5) }\end{array}$} & PSO & 5444.247644 & 0.5617 & 0.1241 & 0.1239 & 0.214 \\
\hline & $\mathrm{ABC}$ & 5443.858545 & 0.5615 & 0.1690 & 0.1685 & 0.309 \\
\hline \multirow{2}{*}{ Ackley } & PSO & 2.52533E-05 & {$[2.77 \mathrm{E}-06,8.49 \mathrm{E}-06]$} & 1.4445 & 1.3523 & 0.263 \\
\hline & $\mathrm{ABC}$ & 0.026980062 & {$[0.0019,0.0086]$} & 1.5845 & 1.4896 & 0.352 \\
\hline \multirow{2}{*}{ Griewank } & PSO & 1.12553E-07 & {$[1.52 \mathrm{E}-04,6.29 \mathrm{E}-04]$} & 2.7993 & 2.7472 & 0.291 \\
\hline & $\mathrm{ABC}$ & 0.013695082 & {$[0.1615,0.0467]$} & 3.7583 & 3.7025 & 0.381 \\
\hline \multirow{2}{*}{ Rastrigin } & PSO & 9.8966E-06 & {$[1.04 \mathrm{E}-04,1.97 \mathrm{E}-04]$} & 1.1807 & 1.0510 & 0.266 \\
\hline & $\mathrm{ABC}$ & 0.304263396 & {$[-0.0108,0.0037]$} & 1.1914 & 0.9682 & 0.327 \\
\hline \multirow{2}{*}{ Schwefel } & PSO & $2.56402 \mathrm{E}-05$ & {$[420.9698,420.9694]$} & 124.7743 & 32.4822 & 0.284 \\
\hline & $\mathrm{ABC}$ & 9.796859674 & {$[413.7217,426.0075]$} & 62.550 & 51.5707 & 0.315 \\
\hline \multirow{2}{*}{ Rosenbrock } & PSO & 2.61713E-05 & {$[1.0048,1.0095]$} & 121.5144 & 120.8452 & 0.268 \\
\hline & $\mathrm{ABC}$ & 0.009721355 & {$[0.9111,0.8344]$} & 106.1114 & 105.6677 & 0.342 \\
\hline \multirow{2}{*}{ Sphere } & PSO & 5.29709E-10 & {$[-1.60 \mathrm{E}-05,1.66 \mathrm{E}-05]$} & 15.4035 & 15.3045 & 0.233 \\
\hline & $\mathrm{ABC}$ & 0.000273577 & {$[0.0068,-0.0151]$} & 19.3378 & 19.2155 & 0.305 \\
\hline
\end{tabular}

In addition to finding the optimum tilt angle $\beta_{\text {opt }}$ for each month, the PSO algorithm can also find daily optimum tilt angles, by simply inputting the day number (instead of the average day number of the month) in (2), and computing the resulting objective function (5) for a particular day. However, as the algorithm utilises the average daily radiation on a horizontal surface, $H$, this means a calculation for daily optimum tilt angles would assume that all days of a month experience the same amount of $H$. Thus, if daily values of $H$ can be determined and used, a better estimation could be achieved for daily optimum tilt values.

It is also important to note that the methods described here to compare the annual solar radiation using different means of choosing tilt angle may be rudimentary, as the PSO algorithm generates predicted values of solar radiation on a tilted surface based on historic climate data; real-time measurements of solar radiation are not collected. Additionally, the performance of the PSO algorithm is assessed here by comparing the different annual solar radiation values obtained using the different methods, and also by comparing the algorithm with the $\mathrm{ABC}$ algorithm using benchmark test functions; while a valid evaluation of the performance of the PSO algorithm is made with a previous study in Brunei Darussalam, and a comparative analysis of quality of results, errors, and execution time with the $\mathrm{ABC}$ algorithm is conducted 
using benchmark test functions, a better assessment indeed would be to compare the PSO algorithm with other metaheuristic algorithms. However, the methods in this paper still provide a starting point from which practical investigations into the optimum tilt angle for a solar panel system in Brunei Darussalam, and other locations around the world, can be conducted.

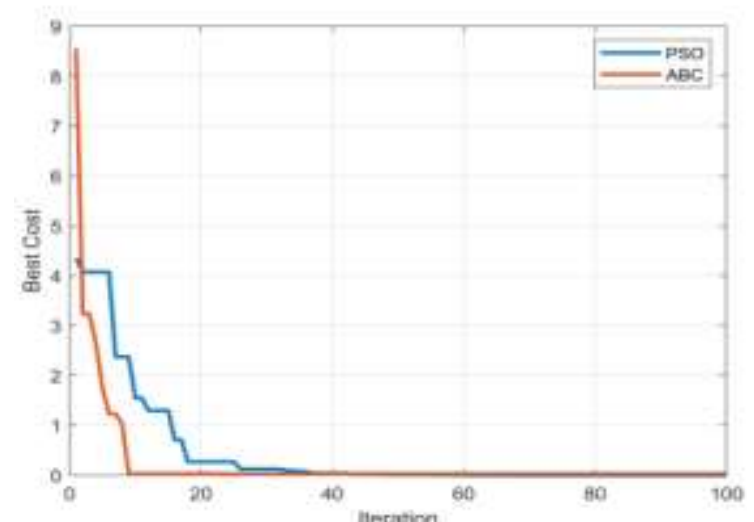

(a) Ackley

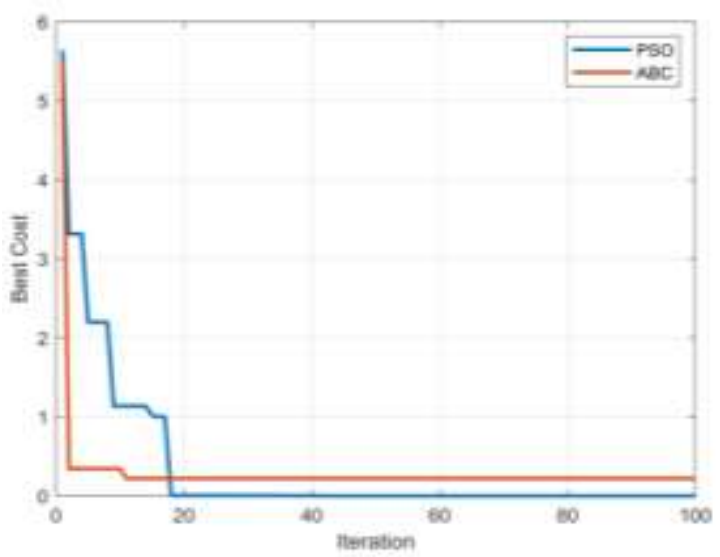

(b) Rastrigin

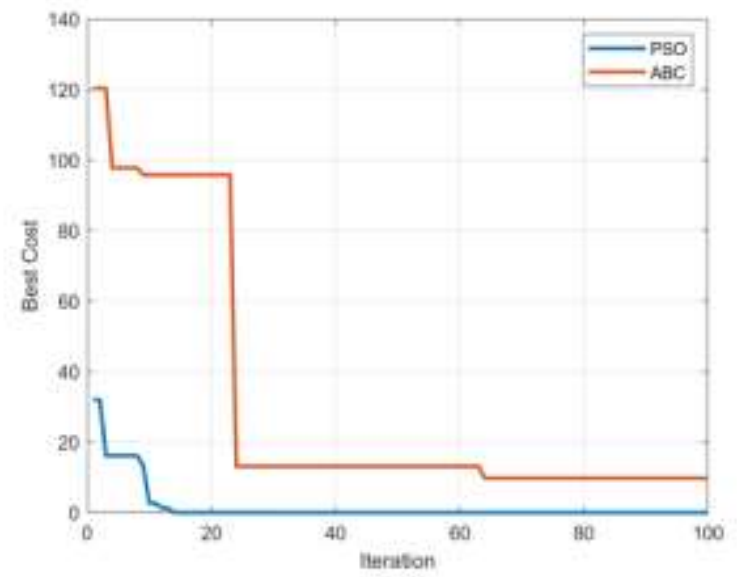

(d) Rosenbrock

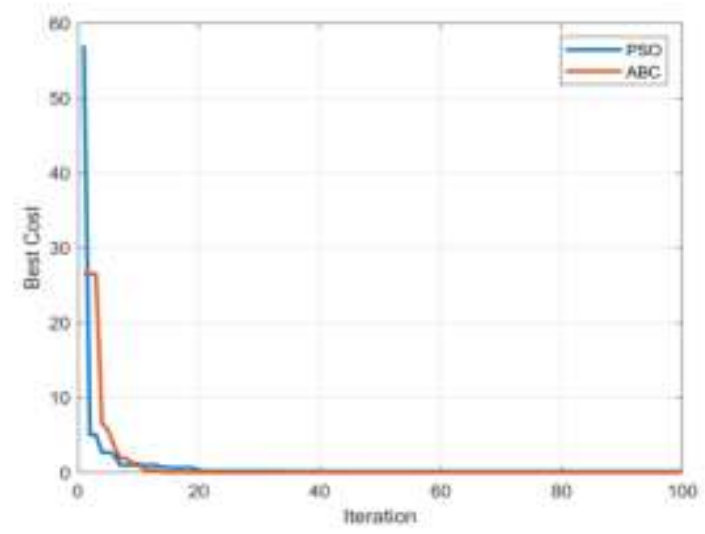

(a) Griewank

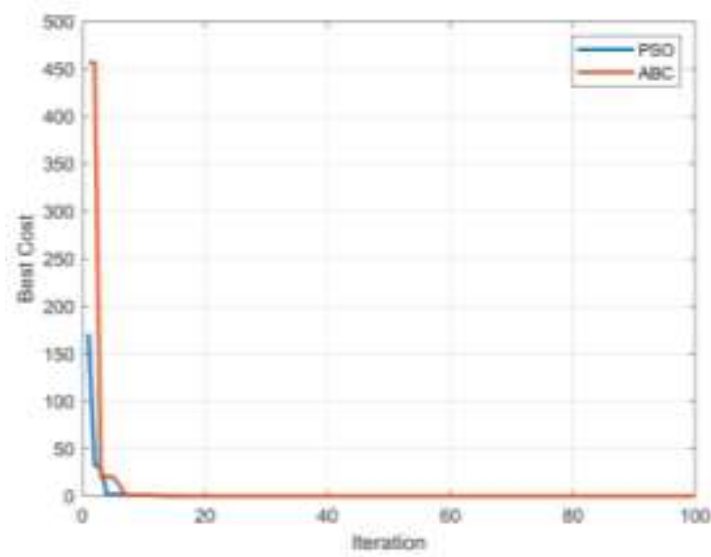

(c) Schwefel

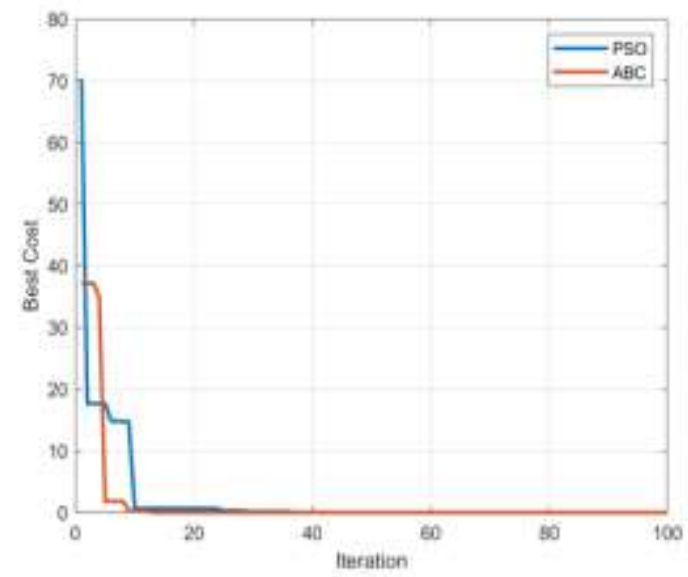

(e) Sphere

Figure 7 (a-e). MATLAB simulations of convergence of PSO and ABC algorithms over 1000 trials 


\section{CONCLUSION}

Choosing the optimum tilt angle for a solar panel is of utmost importance in a PV system, as it affects the annual solar radiation incident on the tilted panel. The findings in this paper illustrate how poorly chosen values of tilt angle can yield lower annual solar radiation, and that tilting a panel to a particular angle can potentially increase the radiation, thereby increasing the energy output of the panel. In this paper, the optimum tilt angle for a location in Brunei Darussalam is determined using the particle swarm optimization (PSO) algorithm. The algorithm recommends a different tilt angle for each month, ranging from $34.7^{\circ}$ in December to $1.3^{\circ}$ in September, and $-26.7^{\circ}$ in June to $-8.9^{\circ}$ in April. The algorithm also recommends changing the orientation of the solar panel from south-facing from January to March, and September to December, and north-facing from April to August. This orientation is indicated by the sign of the angle obtained. A study conducted previously in Brunei Darussalam achieved $4.46 \%$ higher annual solar radiation on a tilted surface than on a horizontal surface; this study employed a manual method of obtaining optimum tilt angles. An increase of $5.87 \%$ is observed when the PSO algorithm is used to determine optimum tilt angles for the same data. The annual solar radiation is $5.76 \%$ higher when the tilt angle is changed every month, as determined by the PSO algorithm, compared to when the tilt angle is fixed at $4.14^{\circ}$, as calculated by averaging the monthly tilt angles. The annual solar radiation achieved when the tilt angle is changed every month is $8.65 \%$ greater than when Lunde's conventional method is used, and $17.31 \%$ greater than when Duffie and Beckman's conventional method is used. Finally, the annual solar radiation is $5.94 \%$ higher when compared with keeping the tilt angle fixed at $0^{\circ}$ throughout the year. It is these improvements in annual solar radiation that corroborates the PSO algorithm's success in determining the optimum tilt angle for each month, and holding the capability of increasing the annual yield of a PV system. A comparative analysis of the PSO algorithm with the ABC algorithm using benchmark test functions reveal the PSO algorithm's superiority over the ABC algorithm, exhibiting lower RMSE and SD, better convergence to the global minimum, more accurate locations of the global minimum, and faster execution times. Its better performance is encouraging, and validates the PSO algorithm's execution in determining the optimum tilt angle for each month. It is expected that the PSO algorithm implemented in this study can be used to compute the optimum tilt angle for PV systems installed in any location, given the latitude. Employing this algorithm in a practical solar panel setup can provide more conclusive evidence that the algorithm is accurate in determining the optimum tilt angle, and increasing the energy output of a solar panel system. It may also prove insightful to conduct more detailed assessments comparing the performance of the PSO algorithm with other metaheuristic algorithms.

\section{COMPETING INTERESTS}

Authors have declared that no competing interests exist.

\section{ACKNOWLEDGEMENTS}

The authors would like to acknowledge the valuable technical support provided by the Electrical and Electronic Engineering Programme Area at Universiti Teknologi Brunei in the completion of this paper.

\section{REFERENCES}

[1] J. A. Duffie, W. A. Beckman, and J. McGowan, "Solar Engineering of Thermal Processes," vol. 53, no. 4. 1985.

[2] P. J. Lunde, "Solar thermal engineering: Space heating and hot water systems," 1980.

[3] R. Tang and T. Wu, "Optimal tilt-angles for solar collectors used in China," Applied energy, vol. 79, pp. 239-248, 2004, doi: 10.1016/j.apenergy.2004.01.003.

[4] H. Yang and L. Lu, "The optimum tilt angles and orientations of PV claddings for Building-Integrated Photovoltaic (BIPV) applications," J. Sol. Energy Eng. Trans. ASME, vol. 129, no. 2, pp. 253-255, 2007, doi: 10.1115/1.2212439.

[5] J. F. Orgill and K. G. T. Hollands, "Correlation equation for hourly diffuse radiation on a horizontal surface," Sol. Energy, vol. 19, no. 4, pp. 357-359, 1977, doi: 10.1016/0038-092X(77)90006-8.

[6] A. M. Ali Morad, A. K. S. Al-Sayyab, and M. A. Abdulwahid, "Optimisation of tilted angles of a photovoltaic cell to determine the maximum generated electric power: A case study of some Iraqi cities," Case Stud. Therm. Eng., vol. 12, no. July, pp. 484-488, 2018, doi: 10.1016/j.csite.2018.07.001.

[7] K. Bakirci, "General models for optimum tilt angles of solar panels: Turkey case study," Renew. Sustain. Energy Rev., vol. 16, no. 8, pp. 6149-6159, 2012, doi: 10.1016/j.rser.2012.07.009.

[8] H. Heywood, "Operating experiences with solar water heating," IHVE J., vol. 39, 1971.

[9] O. Asowata, J. Swart, and C. Pienaar, "Optimum tilt and orientation angles for photovoltaic panels in the Vaal triangle," Asia-Pacific Power Energy Eng. Conf. APPEEC, pp. 63-69, 2012, doi: 10.1109/APPEEC.2012.6307168.

[10] A. I. Ekpenyong, U. M. Anthony, and I. Markson, "Development of Winter Season Optimal Tilt Angle Model for Fixed Tilted Plane PV Installation in Akwa Ibom State, Nigeria,” Math. Softw. Eng., vol. 3, no. 1, pp. 67-77, 2017. 
[11] E. A. Handoyo, D. Ichsani, and Prabowo, "The optimal tilt angle of a solar collector," Energy Procedia, vol. 32, pp. 166-175, 2013, doi: 10.1016/j.egypro.2013.05.022.

[12] H. M. S. Hussein, G. E. Ahmad, and H. H. El-Ghetany, "Performance evaluation of photovoltaic modules at different tilt angles and orientations," vol. 45, pp. 2441-2452, 2004, doi: 10.1016/j.enconman.2003.11.013.

[13] M. A. bin H. M. Yakup and A. Q. Malik, "Optimum tilt angle and orientation for solar collector in Brunei Darussalam," Renew. Energy, vol. 24, no. 2, pp. 223-234, 2001, doi: 10.1016/j.enconman.2009.05.031.

[14] B. Jamil, A. T. Siddiqui, and N. Akhtar, "Estimation of solar radiation and optimum tilt angles for south-facing surfaces in Humid Subtropical Climatic Region of India," Eng. Sci. Technol. an Int. J., vol. 19, no. 4, pp. 18261835, 2016, doi: 10.1016/j.jestch.2016.10.004.

[15] J. V. Herrera-Romero, D. Colorado-Garrido, M. A. Escalante Soberanis, and M. Flota-Bañuelos, "Estimation of the optimum tilt angle of solar collectors in Coatzacoalcos, Veracruz," Renew. Energy, vol. 153, pp. 615-623, 2020, doi: 10.1016/j.renene.2020.02.045.

[16] A. Ullah, H. Imran, Z. Maqsood, and N. Z. Butt, "Investigation of optimal tilt angles and effects of soiling on PV energy production in Pakistan," Renew. Energy, vol. 139, pp. 830-843, 2019, doi: 10.1016/j.renene.2019.02.114.

[17] G. Lewis, "Optimum tilt of a solar collector," Sol. Wind Technol., vol. 4, no. 3, pp. 407-410, 1986.

[18] K. K. Gopinathan, "Solar radiation on variously oriented sloping surfaces," Sol. Energy, vol. 47, no. 3, pp. 173-179, 1991, doi: 10.1016/0038-092X(91)90076-9.

[19] F. Jafarkazemi and S. A. Saadabadi, "Optimum tilt angle and orientation of solar surfaces in Abu Dhabi, UAE," Renew. Energy, vol. 56, pp. 44-49, 2013, doi: 10.1016/j.renene.2012.10.036.

[20] M. Benghanem, "Optimization of tilt angle for solar panel: Case study for Madinah, Saudi Arabia," Appl. Energy, vol. 88, no. 4, pp. 1427-1433, 2011, doi: 10.1016/j.apenergy.2010.10.001.

[21] H. S. S. Pour, H. K. Beheshti, and M. Rahnama, "Environmental Effects The Gain of the Energy Under the Optimum Angles of Solar Panels During a Year in Isfahan, Iran The Gain of the Energy Under the Optimum Angles of Solar Panels During a Year in Isfahan, Iran," Energy Sources, Part A Recover. Util. Environ. Eff., vol. 33, no. 13, pp. 1281-1290, 2011, doi: 10.1080/15567036.2010.549923.

[22] M. Guo et al., "Optimal tilt angle and orientation of photovoltaic modules using HS algorithm in different climates of china," Appl. Sci., vol. 7, no. 10, 2017, doi: 10.3390/app7101028.

[23] T. V. Dixit, A. Yadav, and S. Gupta, "Annual Optimum Tilt Angle Prediction of Solar Collector using PSO Estimator,” IOP Conf. Ser. Mater. Sci. Eng., vol. 225, no. 1, 2017, doi: 10.1088/1757-899X/225/1/012296.

[24] Y. M. Chen, C. H. Lee, and H. C. Wu, "Calculation of the optimum installation angle for fixed solar-cell panels based on the genetic algorithm and the simulated-annealing method," IEEE Trans. Energy Convers., vol. 20, no. 2, pp. 467-473, 2005, doi: 10.1109/TEC.2004.832093.

[25] Y. P. Chang, "An ant direction hybrid differential evolution algorithm in determining the tilt angle for photovoltaic modules," Expert Syst. Appl., vol. 37, no. 7, pp. 5415-5422, 2010, doi: 10.1016/j.eswa.2010.01.015.

[26] Y. P. Chang, "Optimal the tilt angles for photovoltaic modules in Taiwan," Int. J. Electr. Power Energy Syst., vol. 32, no. 9, pp. 956-964, 2010, doi: 10.1016/j.ijepes.2010.02.010.

[27] Y. P. Chang, "Optimal the tilt angles for photovoltaic modules using PSO method with nonlinear time-varying evolution," Energy, vol. 35, no. 5, pp. 1954-1963, 2010, doi: 10.1016/j.energy.2010.01.010.

[28] T. Ismail, N. Bouarroudj, K. Touafek, and N. Bellel, "Optimization of angle of inclination of the hybrid photovoltaic-thermal solar collector using particle swarm optimization algorithm," J. Renew. Sustain. Energy, vol. 6, no. April 2018, 2014, doi: 10.1063/1.4896956.

[29] J. Kennedy and R. Eberhart, "Particle Swarm Optimization," Proc. ICNN'95 - Int. Conf. Neural Networks, vol. 11, no. 1, pp. 111-117, 1995, [Online]. Available: http://ci.nii.ac.jp/naid/10015518367.

[30] R. Eberhart and James Kennedy, "A New Optimizer Using Particle Swarm Theory," Sixth Int. Symp. Micro Mach. Hum. Sci., vol. 0-7803-267, pp. 39-43, 1995, doi: 10.1.1.470.3577.

[31] B. Y. H. Liu and R. C. Jordan, "The interrelationship and characteristic distribution of direct, diffuse and total solar radiation," Sol. Energy, vol. 4, no. 3, pp. 1-19, 1960, doi: 10.1016/0038-092X(60)90062-1.

[32] B. Liu and R. Jordan, "Daily insolation on surfaces tilted towards equator," ASHRAE, vol. 3, no. 10, pp. 53-59, 1961.

[33] S. A. Klein, "Calculation of Monthly Average Insolation on Tilted Surfaces," vol. 19, pp. 325-329, 1977.

[34] NASA, "POWER Data Access Viewer," NASA Prediction of Worldwide Energy Resources, 2020. https://power.larc.nasa.gov/data-access-viewer/.

[35] J. Page, "The Estimation of Monthly Mean Values of Daily Total Short Wave Radiation on Vertical and Inclined Surfaces from Sunshine Records for Latitudes 40N-40S," in United Nations Conference on New Sources of Energy, 1961.

[36] N. K. D. Choudhury, "Solar radiation at New Delhi," Sol. Energy, vol. 7, no. 2, pp. 44-52, 1963, doi: 10.1016/0038-092X(63)90004-5.

[37] G. Stanhill, "Diffuse sky and cloud radiation in Israel," Sol. Energy, vol. 10, no. 2, pp. 96-101, 1966.

[38] D. J. Norris, "Solar radiation on inclined surfaces," Sol. Energy, vol. 10, no. 2, pp. 72-76, 1966, doi: 10.1038/204669a0.

[39] Y. Shi and R. C. Eberhart, "A Modified Particle Swarm Optimizer," Proc. IEEE Conf. Evol. Comput. ICEC, pp. 2675-2679, 1998, doi: 10.1109/ICEMI.2007.4350772.

[40] M. Clerc and J. Kennedy, "The particle swarm-explosion, stability, and convergence in a multidimensional complex space," IEEE Trans. Evol. Comput., vol. 6, no. 1, pp. 58-73, 2002, doi: 10.1109/4235.985692.

[41] R. C. Eberhart and Y. Shi, "Particle swarm optimization: Developments, applications and resources," Proc. IEEE Conf. Evol. Comput. ICEC, vol. 1, pp. 81-86, 2001, doi: 10.1109/cec.2001.934374. 